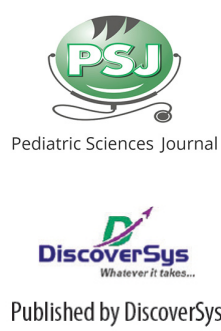

Published by DiscoverSys

\section{The Strategy to Encounter Limited Capacity of Critical Care for COVID-19 Children}

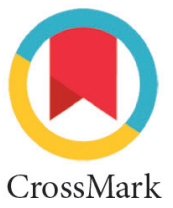

\author{
Saptadi Yuliarto ${ }^{1 *}$
}

\section{COVID-19 PREVALENCE IN CHILDREN POPULATION}

Coronavirus disease (COVID) - 19 morbidity rates in Indonesia have exponentially increased since its first case in March 2020. To date, 15,438 (0.004\%) Indonesian population have been confirmed with Covid-19. Although it is only $0.004 \%$ from all of Indonesian, the patient's enhancement is high, also, the patients who recover just only $21.3 \%$, It would endanger the healthcare capacity in Indonesia. ${ }^{1}$

Recent data from the Indonesian Health Ministry revealed 1,065 (6.9\%) confirmed COVID-19 are at young ages. Considering confirmed to suspected/ probable case ratio was $1: 2.1$, it is estimated that 2,236 children in Indonesia require treatment with COVID-19 protocols. According to the China data's, the prevalence of moderate to critical illness in children was $44.5 \% .{ }^{2}$ If applied in Indonesia, to date, about 995 children need intensive care treatment, which it will rise around 10-40 patients in each day.

\section{THE LIMITATION OF BED AND HEALTH WORKER}

In 2017, the hospital bed to Indonesian population ratio was about 1:1000; which is much lower than the highest ratio in the world, Japan, i.e. 13.1 bed per 1000 people. $^{3}$ This ratio are unequal throughout the provinces; for instance: Jakarta was 2:2000, Sulawesi Selatan 1.53:1000, Jawa Tengah 1.15:1000, and Jawa Timur 1.07:1000. The lowest ratio was Riau (0.98:1000), Kalimantan Tengah (0.91:1000), Banten (0.87:1000), and Jawa Barat (0.85:1000). ${ }^{4}$

These conditions are aggravated by unpreparedness of healthcare facilities. Before pandemic era, most of specialized patient care are concentrated to refererral hospital, whereas only 1-2 are available in every province. Frequently, the hospital was overcapacity. During pandemic, 132 hospitals had been appointed by the Ministry of Health as new referral hospital for COVID-19 patients. In addition, some regional hospitals were also assigned by Governor in each province. Considering 11,123 patients are hospitalized in
Indonesia, with every hospital are able to provide around 10 isolation room, hence, about 1,100 hospitals would be required. It would be difficult to realize at this time.

Aside from bed capacity, the doctor to Indonesian population ratio are relatively low (1:2500), which lead to unequal distribution and overexhaustion. Moreover, the consultant of pediatric emergency and intensive care are only about 100 doctors throughout Indonesia region (ratio to Indonesian children is $1: 796,000$ ). It is complicated by another problems, such as: pharmaceutical and ventilator machines availability, and personal protective equipment (PPE) supplies. These would produce negative impact, especially lack of COVID patient care coverage.

\section{LEVELLING THE HEALTHCARE FACILITIES AND INFRASTRUCTURES}

Data from several countries, especially Italia and China, revealed $90-95 \%$ patients were treated either in the non-ICU isolation room or home isolation. Only $5-10 \%$ suspected patients need intensive care treatment. Based on this data, healthcare level could be organized;for instance, the primary health care and type C-D hospital are categorized as 1st level, type B-C as 2nd level, tupe A-B as 3rd level.

First level health care facilities officiate to carrying patient with mild symptoms. The second level to treat moderate symptoms patients. Furthermore, the third level to treat severe/critical ill/complex cases patients who need sub-specialities treatments. For the diagnostic facilitiy, at the 1st level, no advance methods are needed. Clinical criteria would be useful to make COVID diagnosis; whereas at the 2nd and 3rd level, rapid antibody, rapid antigen, and/or polymerase chain reaction (PCR) test would be needed. In critical care facility, level 1 need to provide simple respiratory support system, such as: low or high flow oxygen, bubble continuous positive airway pressure (CPAP), and pulse oxymetri. Level 2 hospital must have noninvasive ventilation (NIV), CPAP, non-invasive 
vital sign monitor, and $\mathrm{x}$-ray machine. Whereas level 3 hospital must have more complete facilities, that is mechanical ventilation (MV), invasive vital sign monitor, CT scan, portable ultrasonography (USG), and/or extracorporeal life suppot (ECLS).

Each province has to the registry and classifies every health facilities in their region so that health regional cluster system can be formed. This cluster system consists of some level 1-2 health facilities and a level 3 hospital as a regional referral hospital. The sum of the cluster in a province will affiliate in a more prominent health cluster and a leading referral hospital as the centre. The formation of 4-5 regional cluster system will decrease 75-80 of hospital burden from the main referral hospital. With this solution, the main referral hospital can concentrate on treating complex cases or developing new diagnosis and therapeutic technique. The other advantages are decreasing time to get the emergency department to treat for the patients, the range of transportation patients to get proper treatment will be relatively short, prevent the spread of the virus to other regions, and ease case tracking.

Every healthcare facility needs to provide isolation room, level 3 of PPE, and separated track for patient transportation. A negative pressure room does not always required, unless in 3rd level facilities or referral hospital that perform aerosolgeneralized procedure (AGP), such as intubation, nebulization, or bronchoscopy.

\section{COORDINATION SYSTEM AMONG HEALTH CARE FACILITIES}

Telemedicine is a relatively easy way to do health care coordination, discussion, and supervision in this online era. A complicated case can be solved by remote discussion. Patient's condition, laboratory and imaging result could be immediately transferred to the referral hospital, thus the consultant or specialist are able to give some advice to the satellite hospital. Virtual discussion about patient management also could be performed in real time. It will be less time consuming and more cost-effective.

In summary, some solutions to prevent healthcare exhaustion in this pandemic are available. All healthcare facilities have to provide optimum treatment for COVID-19 patients based on their level and capabilities. Coordination system between local/regional, province, and national hospital have to be designed. Finally, every healthcare facility need to upgrade their service capabilities to anticipate a surge in the number of patients.

\section{REFFERENCES}

1. Gugus Tugas Percepatan Penanganan Covid-19. Peta Sebaran. 2020 ; https://covid19.go.id/peta-sebaran.

2. Dong Y, Mo X, Hu Y, et al. Epidemiological characteristics of 2143 pediatric patients with 2019 Coronavirus disease in China. Pediatrics 2020;

3. OECD. Hospital Beds. 2020; https://data.oecd.org/ healtheqt/hospital-beds.htm.

4. Gerintya S. Seberapa Siap Fasilitas \& Tenaga Kesehatan RI Hadapi COVID-19? 2020; https://irto.id/seberapa-siapfasilitas-tenaga-ke.

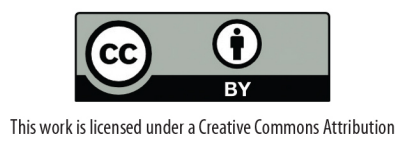

